\title{
Unit Conversion Factor
}

National Cancer Institute

\section{Source}

National Cancer Institute. Unit Conversion Factor. NCI Thesaurus. Code C70774.

An operator used to convert units from one scale to another. 